\title{
Role of nanosilica localization on morphology development of HDPE/PS/PMMA immiscible ternary blends
}

\author{
Z. Javidi ${ }^{1}$, Z. Tarashi ${ }^{1}$, A. Rostami ${ }^{2}$, H. Nazockdast $1^{*}$ \\ ${ }^{1}$ Department of Polymer Engineering and Color Technology, Amirkabir University of Technology, 424 Hafez Ave, \\ Tehran, P. O. Box: 15875-4413, Iran \\ ${ }^{2}$ Polymer Engineering Department, Amirkabir University of Technology, Mahshahr campus, Mahshahr, Iran
}

Received 10 October 2016; accepted in revised form 20 December 2016

\begin{abstract}
In this work, we studied the parameters affecting the localization of hydrophobic nanosilica particles and its impact on morphology development of polyethylene/polystyrene/poly (methyl methacrylate) (HDPE/PS/PMMA) ternary blends, which originally have a thermodynamically preferred core-shell type morphology, by means of a combination of rheology and electron microscopy. An attempt was also made to compare the experimental results with thermodynamic predictions. The ternary blend samples with the same blend ratio but varying in nanosilica loadings were prepared by melt compounding using a laboratory internal mixer. It was demonstrated that the nanosilica localization which could be controlled by the sequence of feeding, would play a significant role in determining the morphology development of the nanofilled ternary blend samples. It was shown that in contrary to thermodynamic prediction of a core shell morphology for the nanofilled samples, the highly enhanced melt elasticity of nanosilica filled polystyrene phase did not allow the PS phase to form a complete encapsulating shell.
\end{abstract}

Keywords: nanocomposites, localization, core-shell morphology, viscoelastic behavior, thermodynamics

\section{Introduction}

In the past two decades, blending of multicomponent polymer with at least three polymer components has received special attention because by utilizing this route it is possible to produce multicomponent blends with new morphologies and improved properties. One of these morphologies that attracted the scientists is the so called core-shell morphology in which one phase (phase 1) encapsulates the droplets (phase 3) in the form of core-shell dispersed in the matrix (phase 2). Obviously, the degree of success to achieve such polymer blends with prescribed properties is strongly influenced by their interfacial interaction. Therefore understanding the role of parameters which control the morphology development of the blends has become important issue for both academic researchers and manufacturers [1-10].
More recently a combination of polymer blending and nanoscale filler reinforcement has received significant attention from both academic and industry groups. This stems from the fact that the addition of nanofiller into immiscible polymer blends has proved to be an efficient method to develop a new family of polymer nanocomposites with a great tailoring potential for producing products with combination of prescribed properties. In this context the localization of nanoparticles has been found to play an important role in determining the resulting morphologies of polymer blends [11-21]. This is why a considerable number of studies have been directed toward understanding parameters controlling the nanoparticle localization in polymer blends. It has been shown that the nanoparticle localization can be determined by thermodynamic parameters and more specifically by

$\overline{{ }^{*} \text { Corresponding author, e-mail: nazdast@aut.ac.ir }}$ (C) BME-PT 
interfacial interaction between the nanoparticles and blend components or kinetic parameters, including the feeding sequence, viscosity of the blend components and mixing conditions [22-24].

It has been shown that the particle-particle and particle-polymer interactions have a major impact on the rheological as well as mechanical enhancement of fumed silica-filled nanocomposites due to the large surface area of particles. Fumed silica fillers have the potential for self-aggregation whose extent depends on their fractal structure and specific area. Hence they can form a network of connected or interacting particles in the molten polymer [25, 26]. Elias and coworkers $[15,16]$ studied the effect of two types of nanosilica (Hydrophobic and hydrophilic silica) on the morphology of polypropylene/ poly(ethylene-covinyl acetate) PP/EVA immiscible blends and their possible migration towards more favorable phase. A significant reduction in the EVA droplets size was observed for both types of silica-filled samples which was mainly attributed to compatibilizing effect of nanofiller. Also they found that the migration of nanoparticles from matrix toward the dispersed phase was more possible compared to the migration from dispersed phase to matrix. The same research group $[12,14]$ have studied the effect of two types of nanosilica (hydrophobic and hydrophilic silica) on the morphology of PP/PS immiscible blend. They reported that stabilization mechanism of PP/PS blend by hydrophilic silica is the reduction in the interfacial tension whereas hydrophobic silica acts as a rigid layer preventing the coalescence of PS droplets. Li et al. [21] investigated on the effect of silica nanoparticles on the morphology and the rheological properties in the immiscible polymer blend poly(carbonate)/poly(methyl methacrylate) (PC/PMMA). They suggested that in the case of hydrophilic filled silica samples, due to the strong interactions between the surface of the particles and the polymer components, migration of the nanoparticles to the PMMA phase could be occurred independent of the compounding sequence. Whereas for the hydrophobic silica, localization at the PC/PMMA interface was the preferred state. They also found that compared to the hydrophilic silica, a better compatibilization can be obtained by accumulating the hydrophobic silica particles at the PC/PMMA interface as the solid barrier. Foudazi and Nazockdast [26, 27] compared the localization of classical compatibilizers and silica fillers, as a new potential type of compatibilizers in
PP/LCP blends, by using rheological methods. Their results showed that while the hydrophilic nanosilica particles localized in both matrix and the LCP dispersed phases, the hydrophobic silica accumulated in the interface and had some compatibilizing effect on PP/LCP blend samples. Based on rheological and morphological studies, they found that hydrophobic silica has higher tendency for aggregation and forms larger and denser aggregates compared to the hydrophilic silica. The lower percolation threshold and the higher fractal dimension for hydrophilic silica compared with hydrophobic one, was attributed to its stronger particle-particle interaction rather than polymer-particle interaction. They suggested that the addition of hydrophobic silica to the PP/LCP blends could play as compatibilizer, whereas the hydrophilic silica mostly works as a thickening agent and suppresses the coalescence.

In the present work, the effect of hydrophobic nanosilica particles on the morphology development of HDPE/PS/PMMA immiscible ternary blends, was studied by using a combination of rheology and electron microscopy techniques. An attempt was also made to compare the experimental results with the thermodynamic predictions. We limited our study to blend compositions with matrix-dispersed morphology; in order to make sure that the hydrodynamic interactions between neighboring core-shell droplets could be ignored. In the first part of this work, the effect of nanosilica particles on the morphology development of ternary blends was investigated through the thermodynamic studies. In the second part, the localization of nanofiller and its effect on the core shell morphology development of the sample were investigated by using by melt viscoelastic measurements. In the last part, the scanning electron microscopy (SEM) was employed to provide more evidences to study the morphology development.

\section{Exprimental}

\subsection{Materials}

A commercial grade high density poly(ethylene) (HDPE) (B4660AB) supplied by SABIC (Saudi Basic Industries Corporation, Riyadh, Saudi Arabia) was used as a matrix. A poly(methylmethacrylate) (PMMA) (cm-205) purchased from CHI MEI corporation (Rende District, Taiwan) and a commercial poly(styrene) (PS) (G-144) supplied by Dongbu Hannong Chemical (Seoul, Korea) were used as minor phases. Fumed nanosilica Aerosil R816 abbreviated 
Table 1. The properties of materials that were used

\begin{tabular}{|l|c|c|c|c|}
\hline \multicolumn{1}{|c|}{ Material } & Grade & $\begin{array}{c}\text { Density } \\
{\left[\mathbf{g} / \mathbf{c m}^{3}\right]}\end{array}$ & $\begin{array}{c}\text { MFI } \\
{[\mathbf{g} / \mathbf{1 0} \mathbf{~ m i n}]}\end{array}$ & Supplier \\
\hline HDPE & B4660AB & 0.96 & $\begin{array}{c}0.7 \\
\left(190^{\circ} \mathrm{C} / 2.16 \mathrm{~kg}\right)\end{array}$ & SABIC \\
\hline PS & G-144 & 1.04 & $\begin{array}{c}8.5 \\
\left(200^{\circ} \mathrm{C} / 5 \mathrm{~kg}\right)\end{array}$ & Dongbu Hannong Chemical \\
\hline PMMA & ACRYREX cm-205 & 1.19 & $\begin{array}{c}1.8 \\
\left(230^{\circ} \mathrm{C} / 1.8 \mathrm{~kg}\right)\end{array}$ & CHI MEI \\
\hline Anti oxidant & $\begin{array}{c}1 \text { Ciba Specialty Chemicals } \\
\text { B-225 }\end{array}$ & $0.53-0.63$ & - & \\
\hline
\end{tabular}

Table 2. The properties of nanosilica particles

\begin{tabular}{|c|c|c|c|c|c|c|}
\hline $\begin{array}{c}\text { AEROSIL } \\
\text { grades }\end{array}$ & $\begin{array}{c}\text { BET surface area } \\
{\left[\mathbf{m}^{\mathbf{2}} / \mathbf{g}\right]}\end{array}$ & $\begin{array}{c}\text { Loss on drying } \\
{[\mathbf{w t} \%]}\end{array}$ & $\mathbf{p H}$ & $\begin{array}{c}\text { Carbon content } \\
{[\mathbf{w t} \mathbf{\%}]}\end{array}$ & $\begin{array}{c}\text { Density } \\
{\left[\mathbf{g} / \mathbf{c m}^{\mathbf{3}}\right]}\end{array}$ & Supplier \\
\hline AEROSIL $^{\circledR} \mathrm{R} 816$ & $190 \pm 20$ & $<1.0$ & $4.0-5.5$ & $0.9-1.8$ & 2 & Evonic Degussa GmbH \\
\hline
\end{tabular}

as msilica was kindly supplied by Evonic Degussa GmbH (Hanau, Germany). The Aerosil R816 is hexadecylsilane surface treated hydrophobic nanosilica based on Aerosil 200. The specifications of the materials used, are given in Table 1 and Table 2.

\subsection{Sample preparation}

The unfilled and nanosilica filled blends with different compositions, all prepared by melt compounding using a Brabender internal mixer (Duisburg, Germany) are listed in Table 3. $0.1 \mathrm{wt} \%$ Irganox B225 (Ciba Specialty Chemicals, Basel, Switzerland) was used in order to minimize the thermal degradation of components during melt blending. In order to investigate the effect of feeding sequence on localization of silica nanoparticles and its effect on morphology development, three feeding routes were used namely; sequential feeding(route 1), PS based masterbatch feeding (route 2) and PMMA masterbatch feeding (route 3). In route (1)the HDPE and PMMA and msilica were first melt blended for 10 minutes and the PS was added into the mixture in the later stage. In route (2) a master batch of silica filled PS was first prepared and then appropriate amount of resulting master batch was melt mixed with the other two components following the same sequence as route one to prepare HDPE/PS/PMMA/silica nanocomposites. Route (3) was similar to second route but with using silica filled PMMA phase as a master batch. The coding of the nanocomposite samples in Table 3 were arranged by $\mathrm{N}$ as nanocomposite, $\mathrm{T}$ as ternary blend (HDPE/PS/PMMA), $\mathrm{R}(\mathrm{x})$ as the route of feeding and finally the nanosilica content in the nanocomposites came before the sequence of feeding
Table 3. Compositions of the samples

\begin{tabular}{|l|c|c|c|c|c|}
\hline $\begin{array}{c}\text { Sample } \\
\text { code }\end{array}$ & $\begin{array}{c}\text { HDPE } \\
\text { [wt\%] }\end{array}$ & $\begin{array}{c}\text { PS } \\
\text { [wt\%] }\end{array}$ & $\begin{array}{c}\text { PMMA } \\
\text { [wt\%] }\end{array}$ & $\begin{array}{c}\text { Msilica } \\
\text { [wt \%] }\end{array}$ & $\begin{array}{c}\text { Order of } \\
\text { feeding }\end{array}$ \\
\hline T20 & 80 & 7.00 & 13.00 & 0 & - \\
\hline NPE2 & 98 & 0 & 0 & 2.00 & - \\
\hline NPE6 & 94 & 0 & 0 & 6.00 & - \\
\hline NPS2 & 0 & 98.00 & 0 & 2.00 & - \\
\hline NPS6 & 0 & 94.00 & 0 & 6.00 & - \\
\hline NPMMA2 & 0 & 0 & 98.00 & 2.00 & - \\
\hline NPMMA6 & 0 & 0 & 94.00 & 6.00 & - \\
\hline NT0.15R1 & 80 & 6.85 & 13.00 & 0.15 & 1 \\
\hline NT0.26R1 & 80 & 7.00 & 12.74 & 0.26 & 1 \\
\hline NT0.42R1 & 80 & 6.58 & 13.00 & 0.42 & 1 \\
\hline NT1R1 & 79 & 7.00 & 13.00 & 1.00 & 1 \\
\hline NT3R1 & 77 & 7.00 & 13.00 & 3.00 & 1 \\
\hline NT5R1 & 75 & 7.00 & 13.00 & 5.00 & 1 \\
\hline NT0.15R2 & 80 & 6.85 & 13.00 & 0.15 & 2 \\
\hline NT0.42R2 & 80 & 6.58 & 13.00 & 0.42 & 2 \\
\hline NT0.26R3 & 80 & 7.00 & 12.74 & 0.26 & 3 \\
\hline NT0.78R3 & 80 & 7.00 & 12.22 & 0.78 & 3 \\
\hline
\end{tabular}

of the samples. In order to make sure a core-shell type morphology development for the unfilled sample as the original reference, a ternary blend sample (HDPE/PS/PMMA) with total amount of $20 \mathrm{wt} \%$ of dispersed phases (PS+PMMA) designated as T20 was prepared. This sample was prepared by first melt mixing of HDPE and PMMA and adding the PS after 10 minutes.

\subsection{Sample characterization}

The surface tension of the blend components and nanosilica filled components were measured using the contact angle method utilizing KRUSS K14 Tensiometer (Germany) at $25^{\circ} \mathrm{C}$. The solid samples, which were shaped in plate form, were immersed in 
water and formamide. The contact angle $(\theta)$ was calculated from the measured force $\left(F_{1}\right)$ by transposing Wilhelmy equation (Equation (1)):

$\theta=\cos ^{-1}\left(\frac{F_{1}}{p \gamma}\right)$

where $p$ and $\gamma$ are the wetted length (perimeter at the level of the liquid surface) and surface tension, respectively [28]. The surface free energy of the solid samples calculated at $25^{\circ} \mathrm{C}$ by Wilhelmy contact angle method are given in Table 4 and Table 5. Surface tension of polymers usually vary linearly with temperature, with the slope $(-(\mathrm{d} \gamma / \mathrm{d} T))$ of about $0.05 \mathrm{mN} / \mathrm{m}$ [29]. The Guggenheim equation (Equation (2)) [30] developed for small-molecule liquids, has been found to apply to polymers:

$$
-\frac{\mathrm{d} \gamma}{\mathrm{d} T}=\frac{11}{9} \frac{\gamma_{0}}{T_{\mathrm{c}}}\left(1-\frac{T}{T_{\mathrm{c}}}\right)^{2 / 9}
$$

where the $\gamma_{0}$ is the surface tension at $T=0 \mathrm{~K}$ and $T_{\mathrm{c}}$ is the critical temperature. The value of $\gamma_{0}$ and $T_{\mathrm{c}}$ are given in literature [29]. The surface tension of the blend components calculated by Equation (2) at the processing temperature $\left(T=220^{\circ} \mathrm{C}\right)$, are shown in Table 4 and Table 5.

The melt linear viscoelastic behavior of the samples was studied by using rheometric mechanical spectrometry. The oscillatory shear measurements were carried out at $220^{\circ} \mathrm{C}$ using a MCR rheometer (Paar Physica UDS 200, Germany), with parallel plate geometry with a diameter of $25 \mathrm{~mm}$ and a gap of $1 \mathrm{~mm}$. The dynamic strain amplitude sweep experiments were performed in order to determine the linear viscoelastic region by monitoring storage modulus. Melt linear viscoelastic behavior of the samples was studied using frequency sweep experiments in small strain oscillatory shear deformations.

Morphology of the blend samples was examined by a Philips scanning electron microscopy (SEM) (Philips, Amsterdam, Netherlands). The SEM micrographs were taken from cryogenically fractured surfaces of the blend samples. All the fractured surfaces were coated with a thin layer of gold before viewing. The brittle behavior of the PS shell could improve the phase contrast in morphology examination of cryogenically surface in SEM micrographs [31]. However, to achieve better contrast between phases in ternary blends, the fractured surfaces were etched in PS solvent (Cyclohexane) at room temperature for about 24 hours. The average dimeter of the dispersed particles (core-shell) were measured by using Image $\mathrm{J}$ software.

\section{Results and discussion}

\subsection{Thermodynamic prediction of the nanofilled and unfilled ternary polymer blends morphologies}

Based on thermodynamic studies, Hobbs et al. [32] rewrote the Harkin [33] equation for a ternary system with component 2 as continuous phase and 1 and 3 as dispersed phases. Accordingly, the spreading coefficients $\lambda_{13}$ and $\lambda_{31}$ are calculated as shown by Equations (3) and (4):

$$
\begin{aligned}
& \lambda_{13}=\gamma_{23}-\gamma_{21}-\gamma_{13} \\
& \lambda_{31}=\gamma_{21}-\gamma_{23}-\gamma_{13}
\end{aligned}
$$

where $\gamma_{\mathrm{ij}}$ is the interfacial tensions for each compo-

\begin{tabular}{|c|c|c|c|c|c|c|c|c|}
\hline Polymers & $\begin{array}{c}\gamma \text { at } 25^{\circ} \mathrm{C} \\
{[\mathrm{mN} / \mathrm{m}]}\end{array}$ & $\begin{array}{c}\gamma \text { at } 220^{\circ} \mathrm{C} \\
{[\mathrm{mN} / \mathrm{m}]}\end{array}$ & $\begin{array}{c}\gamma_{\mathrm{d}} \text { at } 220^{\circ} \mathrm{C} \\
{[\mathrm{mN} / \mathrm{m}]}\end{array}$ & $\begin{array}{c}\gamma_{\mathrm{p}} \text { at } 220^{\circ} \mathrm{C} \\
{[\mathrm{mN} / \mathrm{m}]}\end{array}$ & $X^{p}$ polarity & $\begin{array}{c}\gamma_{0} \\
{[\mathrm{mN} / \mathrm{m}]}\end{array}$ & $\begin{array}{c}T_{\mathrm{c}} \\
{[\mathrm{K}]}\end{array}$ & $\begin{array}{c}(-\mathbf{d} \gamma / \mathbf{d} T) \\
{[\mathrm{mN} /(\mathbf{m} \cdot \mathbf{K})]}\end{array}$ \\
\hline HDPE & 33.8 & 22.7 & 17.2 & 5.5 & 0.242 & 53.7 & 1032 & 0.057 \\
\hline PS & 27.7 & 13.6 & 7.7 & 5.9 & 0.438 & 63.3 & 967 & 0.072 \\
\hline PMMA & 31.9 & 17.1 & 4.7 & 12.4 & 0.724 & 65.1 & 935 & 0.076 \\
\hline Msilica & 81.7 & 62.2 & 54.7 & 7.5 & 0.12 & - & - & 0.100 \\
\hline
\end{tabular}
nent pair. A positive value of $\lambda_{13}$ and negative value

Table 4. The surface tension of components

Table 5. The surface tension of silica filled components

\begin{tabular}{|l|c|c|c|c|c|c|}
\hline \multicolumn{1}{|c|}{ Polymers } & $\begin{array}{c}\gamma \mathbf{a t ~ 2 0}{ }^{\circ} \mathbf{C} \\
{[\mathbf{m N} / \mathbf{m}]}\end{array}$ & $\begin{array}{c}\gamma \text { at 220 } \\
{[\mathbf{m} \mathbf{~} / \mathbf{m}]}\end{array}$ & $\begin{array}{c}\gamma_{\mathbf{d}} \text { at 220 } \\
{[\mathbf{m N} / \mathbf{m}]}\end{array}$ & $\begin{array}{c}\gamma_{\mathbf{p}} \mathbf{a t ~ 2 2 0}{ }^{\circ} \mathbf{C} \\
{[\mathbf{m N} / \mathbf{m}]}\end{array}$ & $X^{\mathbf{p}}$ polarity & $\begin{array}{c}(-\mathbf{d} \gamma / \mathbf{d} \mathbf{T}) \\
{[\mathbf{m N} /(\mathbf{m} \cdot \mathbf{K})]}\end{array}$ \\
\hline NPE2 & 35.1 & 23.9 & 13.80 & 10.2 & 0.424 & 0.057 \\
\hline NPS2 & 38.1 & 24.1 & 16.70 & 7.3 & 0.304 & 0.072 \\
\hline NPMMA2 & 35.8 & 20.9 & 6.45 & 14.5 & 0.692 & 0.076 \\
\hline
\end{tabular}




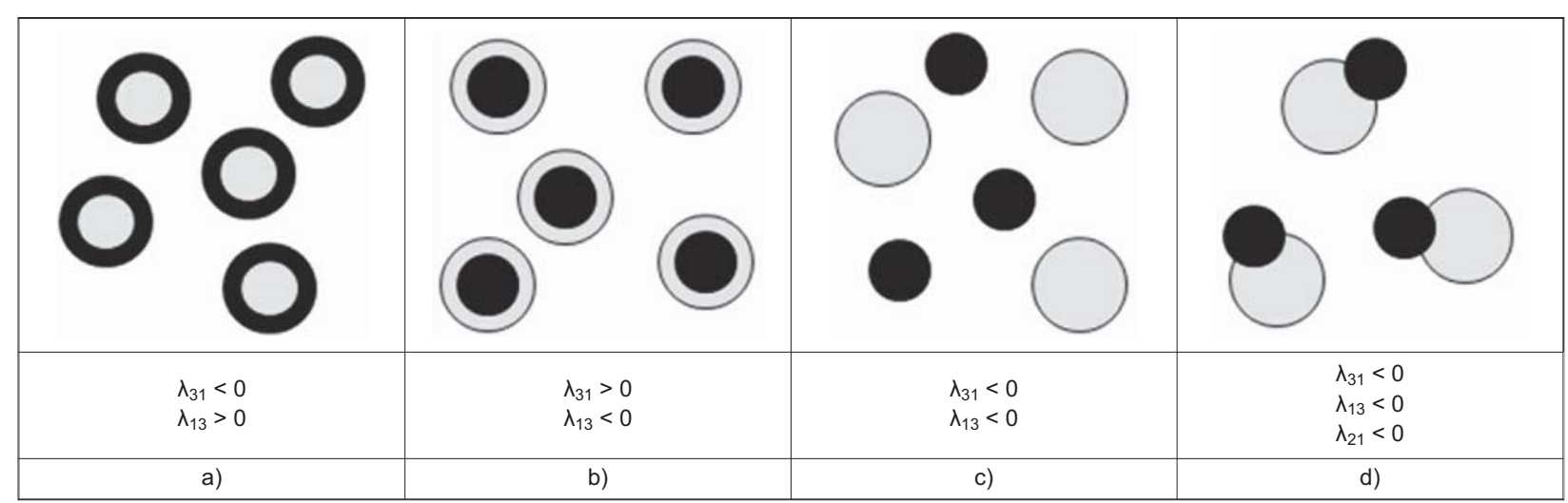

Figure 1. Schematic of different phase morphologies predicted by their spreading coefficients, phase 1 is black, phase 2 is the matrix (white) and phase 3 is grey, a) core shell morphology with phase 1 as the shell, b) core shell morphology with phase 3 as the shell, c) matrix-dispersed morphology with phase 1 and phase 3 as the dispersed droplets and d) partial encapsulation of phase 1 and 3 in phase 2 as matrix

of $\lambda_{31}$ will lead to encapsulation of phase 3 by phase 1 . In the case where both $\lambda_{31}$ and $\lambda_{13}$ are negative and $\lambda_{21}$ is positive, two minor components form separately dispersed phases but if $\lambda_{13}, \lambda_{31}$ and $\lambda_{21}$ are all negative, one phase will partially encapsulate the others [2]. Different phase morphologies predicted by the spreading coefficiens are schematically shown in Figure 1. In later studies Guo and coworkers $[34,35]$ extended the spreading coefficient approach to take into account the overall surface free energy by considering the interfacial area. For any type of morphology the free energy of mixing can be written as Equation (5):

$G=\sum_{\mathrm{i}} n_{\mathrm{i}} \mu_{\mathrm{i}}+\sum_{\mathrm{i} \neq \mathrm{j}} A_{\mathrm{ij}} \gamma_{\mathrm{ij}}$

where $\mu_{\mathrm{i}}$ is the chemical potential of $i, n_{\mathrm{i}}$ is the number of moles of $i, A_{\mathrm{ij}}$ is the interfacial area between components $i$ and $j$ and $\gamma_{\mathrm{ij}}$ is the interfacial tension between components $i$ and $j$. The lowest value of $\left(\sum A_{\mathrm{ij}} \gamma_{\mathrm{ij}}\right)$ will correspond to the lowest value of Gibbs morphology [3, 7, 8, 36-38]. Accordingly, the morphology of multiphase systems can be controlled through changing the interfacial interaction between the blend components [39].

The surface tension values (total, polar and dispersive) of the blend components with and without silica that were measured at $25^{\circ} \mathrm{C}$ and extrapolated to the processing temperature (Equation (2)), are shown in Table 4 and Table 5 . The interfacial tension values between the polymer components and their nanocomposite pairs calculated by Harmonic mean equation (Equation 6) are listed in Table 6:

$\gamma_{i j}=\gamma_{i}+\gamma_{j}-\frac{4 \gamma_{i}^{p} \gamma_{j}^{p}}{\gamma_{i}^{p}+\gamma_{j}^{p}}-\frac{4 \gamma_{i}^{d} \gamma_{j}^{d}}{\gamma_{i}^{d}+\gamma_{j}^{d}}$ where $\gamma_{\mathrm{i}}$ and $\gamma_{\mathrm{j}}$ are the surface energy of two polymers $i$ and $j$, and the superscripts $d$ and $p$ denote the dispersion and polar components of the surface energy, respectively. The interfacial tensions between the silica nanoparticles and blend components measured through the geometric mean equation introduced by $\mathrm{Wu}$ (Equation (7)) [29], are shown in Table 6:

$$
\gamma_{i j}=\gamma_{i}+\gamma_{j}-2 \sqrt{\gamma_{i}^{d} \gamma_{j}^{d}}-2 \sqrt{\gamma_{i}^{p} \gamma_{j}^{p}}
$$

Results of the spreading coefficient and the relative interfacial energy calculated based on Hobbs and Guo's equations [34, 35] for probable phase structures are given in Table 7. According to these results, the relative interfacial energy and the spreading coefficient are in the follow orders:

Table 6. The interfacial tension of componenet pairs

\begin{tabular}{|l|c|l|c|}
\hline Polymer pairs & $\begin{array}{c}\gamma_{\mathbf{1 2}} \mathbf{2 2 0}{ }^{\circ} \mathbf{C} \\
{[\mathbf{m N} / \mathbf{m}]}\end{array}$ & Polymer pairs & $\begin{array}{c}\gamma_{\mathbf{1 2}} \mathbf{2 2 0}{ }^{\circ} \mathbf{C} \\
{[\mathbf{m N} / \mathbf{m}]}\end{array}$ \\
\hline PE/PS & $3.64^{\mathrm{a}}$ & PE/NPS2 & $0.26^{\mathrm{a}}$ \\
\hline PS/PMMA & $2.95^{\mathrm{a}}$ & PE/NPMMA2 & $8.94^{\mathrm{a}}$ \\
\hline PE/PMMA & $9.74^{\mathrm{a}}$ & PS/NPE2 & $2.83^{\mathrm{a}}$ \\
\hline PE/msilica & $10.73^{\mathrm{b}}$ & PS/NPMMA2 & $3.69^{\mathrm{a}}$ \\
\hline PS/msilica & $21.47^{\mathrm{b}}$ & PMMA/NPE2 & $4.68^{\mathrm{a}}$ \\
\hline PMMA/msilica & $27.94^{\mathrm{b}}$ & PMMA/NPS2 & $8.03^{\mathrm{a}}$ \\
\hline
\end{tabular}

${ }^{a}$ Calculated by Harmonic mean equation.

${ }^{b}$ Calculated by Geometric mean equation.

Table 7. Spreading coefficient and relative interfacial energy in the ternary system

\begin{tabular}{|l|r|l|r|}
\hline \multicolumn{4}{|c|}{ HDPE/PS/PMMA } \\
\hline \multicolumn{2}{|c|}{$\begin{array}{c}\text { (Spreading coefficient) } \\
{[\mathbf{m N} / \mathbf{m}]}\end{array}$} & \multicolumn{2}{c|}{ (RIE) } \\
\hline PS/PMMA & 3.15 & PS+PMMA & 12.31 \\
\hline PMMA/PS & -9.05 & PS/PMMA & 7.90 \\
\hline PE/PMMA & -10.35 & PMMA/PS & 15.49 \\
\hline
\end{tabular}


Table 8. Spreading coefficient and relative interfacial energy in the nanocomposite samples based on ternary blends

\begin{tabular}{|l|r|r|r|}
\hline \multicolumn{2}{|c|}{ PE/NPS2/PMMA } & \multicolumn{2}{c|}{ PE/PS/NPMMA2 } \\
\hline $\begin{array}{c}\lambda \text { (Spreading coefficient) } \\
\text { [mN/m] }\end{array}$ & \multicolumn{2}{c|}{$\begin{array}{c}\boldsymbol{c} \text { (Spreading coefficient) } \\
\text { [mN/m] }\end{array}$} \\
\hline NPS2/PMMA & 1.44 & PS/NPMMA2 & 1.61 \\
\hline PMMA/NPS2 & -17.51 & NPMMA2/PS & -8.99 \\
\hline NPE2/PMMA & -1.92 & PE/NPMMA2 & -8.89 \\
\hline \multicolumn{2}{|c|}{ (RIE) } & \multicolumn{2}{c|}{ (RIE) } \\
\hline NPS2+PMMA & 9.93 & PS+NPMMA2 & 11.58 \\
\hline NPS2/PMMA & 8.39 & PS/NPMMA2 & 8.70 \\
\hline PMMA/NPS2 & 19.23 & NPMMA2/PS & 14.99 \\
\hline
\end{tabular}

$\lambda_{\text {PS/PMMA }}>0, \lambda_{\text {PMMA/PS }}, \lambda_{\text {PE/PMMA }}<0$, $\mathrm{RIE}_{\mathrm{PS} / \mathrm{PMMA}}<\mathrm{RIE}_{\mathrm{PS}+\mathrm{PMMA}}<\mathrm{RIE}_{\mathrm{PMMA} / \mathrm{PS}}$,

These results predicted a core-shell type morphology in which the PMMA phase was encapsulated by PS shell. This was in agreement with those reported by Reignier and coworkers $[6,7]$ for the similar systems. Similar thermodynamic parameters were calculated for the nanosilica filled blend samples and the results are given in Table 8 . As it can be seen, the spreading coefficient of $\lambda_{\mathrm{NPS} 2 / \mathrm{PMMA}}$ and $\lambda_{\mathrm{PS} / \mathrm{NPMMA} 2}$ are positive regardless of sequence of feeding and their related RIE have the lowest value among different probable structures. This suggests that the presence of msilica did not change the polarity difference between phases appreciably and therefore, core-shell type morphology of these samples remained unchanged in the presence of silica.

The localization of nanoparticles in polymer blends was predicted by estimating the interfacial interactions between three components (two polymers and one filler). The balance of interaction energies was predicted by calculating the wetting parameter $w a_{\mathrm{AB}}$ using Equation (8):

$w a_{\mathrm{AB}}=\frac{\gamma_{\text {filler }-\mathrm{B}}-\gamma_{\text {filler }-\mathrm{A}}}{\gamma_{\mathrm{A}-\mathrm{B}}}$

where $\gamma_{\text {filler-A }}$ and $\gamma_{\text {filler-B }}$ are the interfacial tensions between the filler and polymer $A$ or $B$, respectively and $\gamma_{\mathrm{A}-\mathrm{B}}$ is the interfacial tension between polymer $A$ and $B$ [19]. Accordingly, if $w a>1$, the filler is located within $A$-phase, if $-1<w a<1$, the filler concentrates at the interface and if $w a<-1$, the filler is selectively distributed in the $B$-phase. The wetting parameters calculated for polymer pairs containing silica in the HDPE/PS/PMMA ternary blend are illustrated in the Table 9. These results imply that the
Table 9. The wetting parameter of polymer pairs

\begin{tabular}{|l|c|c|}
\hline \multicolumn{1}{|c|}{$\boldsymbol{A}, \boldsymbol{B}$} & $\boldsymbol{w} \boldsymbol{a}_{\mathrm{AB}}$ & Location \\
\hline PE,PS & 2.95 & PE \\
\hline PS,PMMA & 2.19 & PS \\
\hline PMMA,PE & -1.76 & PE \\
\hline
\end{tabular}

sequence of feeding can play an important role in determining the nanosilica localization.

\subsection{Rheological results: Determination of nanosilica localization in the ternary blends}

Figure 2 shows the storage modulus and complex viscosity versus frequency obtained for unfilled and nanosilica filled polymer components with different loadings (2,6 wt $\%$ ). As can be observed in Figure 2a and $2 b$, the addition of $2 \mathrm{wt} \%$ nanosilica decrease the storage modulus and complex viscosity of the HDPE. A similar effect was reported for nanosilica filled HDPE by Jain et al. [40] and Maurer et al. [41] who attributed it to the selective adsorption of long polymer chains on the nanoparticles surfaces. Accordingly adsorption of high molar mass chains on the surface of nanoparticles eventually results in a reduction in entanglement density and therefore reducing the viscosity. However as seen in the same figure, further increase in nanosilica loadings up to $6 \mathrm{wt} \%$ led to a pronounced increase in $G^{\prime}$ and $\eta^{*}$ particularly in low frequency range. Moreover, the nanosilica induced viscosity enhancement was found to be much greater than due to hydrodynamic effect of nanoparticles predicted from Einstein equation. Thus this behavior could be caused by another mechanism involved with confinement and bridging effects of the matrix molecules. As Jain et al. [40] suggested this is a dominating mechanism when the interparticle distance becomes less than gyration radius $\left(R_{\mathrm{g}}\right)$.

As it is seen in Figure 2c and 2d PS containing $6 \mathrm{wt} \%$ nanosilica exhibits a pronounced viscosity upturn and a plateau region in $G^{\prime}$ at the low frequencies. Similar results were reported for the nanocomposites containing nanosilica by Cassagnau who related this behavior to formation of a 3D-network type structure [25]. The network structure in the nanosilica filled PS system can be formed by partly adsorption of polymer chains on the filler surface and partly entanglement with neighboring ones [42].

The results of similar experiments performed on nanosilica filled PMMA are shown in Figure 2e and $2 \mathrm{f}$. It is evident that the addition of silica up to $6 \mathrm{wt} \%$ 

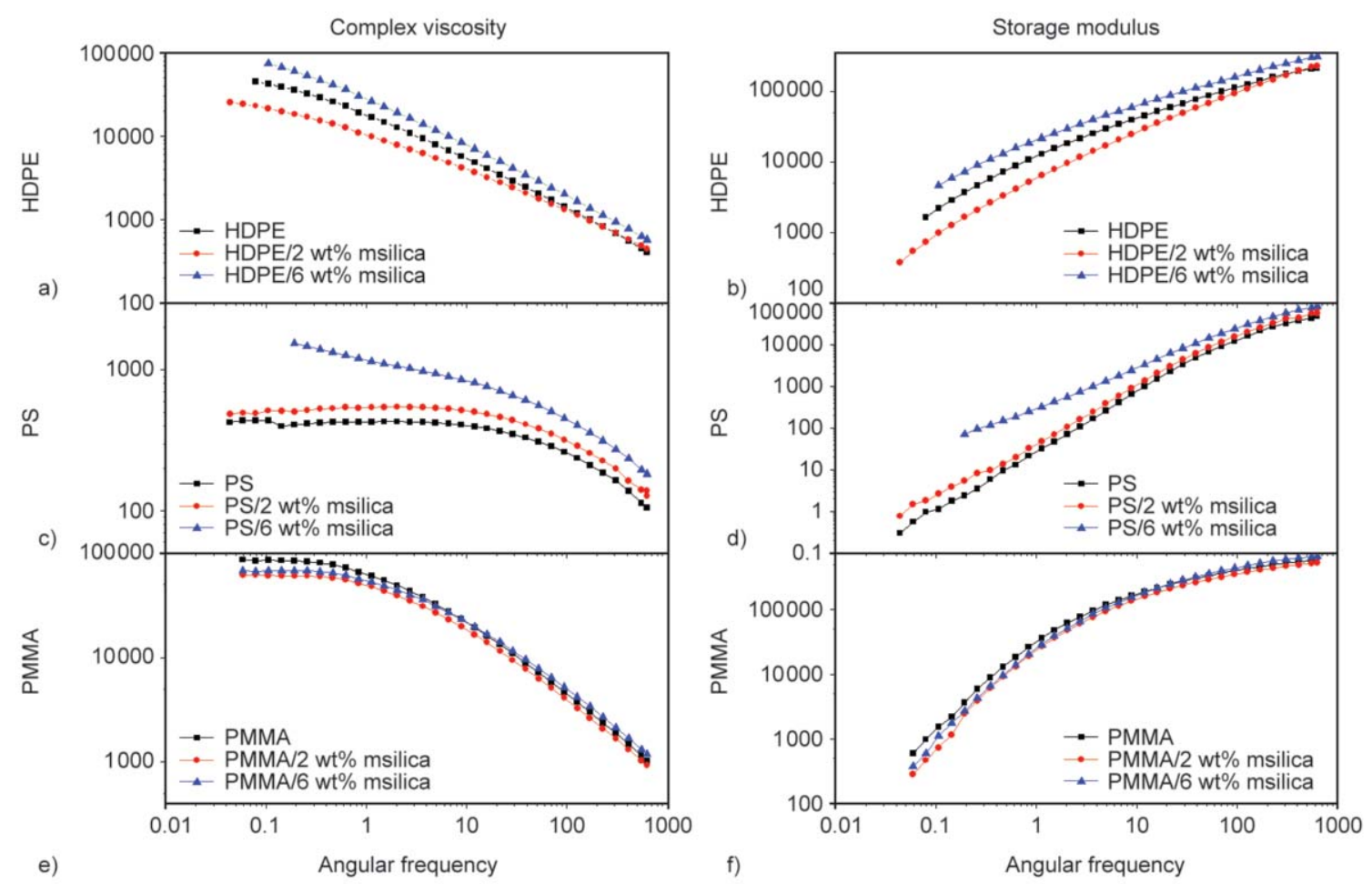

Figure 2. Storage modulus and complex viscosity versus frequency for the (a, b) nanofilled PE, (c, d) nanofilled PS and (e, f) nanofilled PMMA.

did not have appreciable effect on viscoelastic properties of the PMMA matrix. This is an indication of weak interfacial interactions between nanosilica and PMMA matrix. Consequently neither particle-particle nor particle-polymer interactions are strong enough to change the viscoelastic behavior of PMMA matrix. The results of viscoelastic measurements performed on unfilled and nanosilica filled ternary blend samples (T20:HDPE/PS/PMMA, 80/7/13 wt\%) with different silica loadings prepared by the first feeding route are shown Figure 3. By comparing these results with those observed for HDPE and nanosilica filled

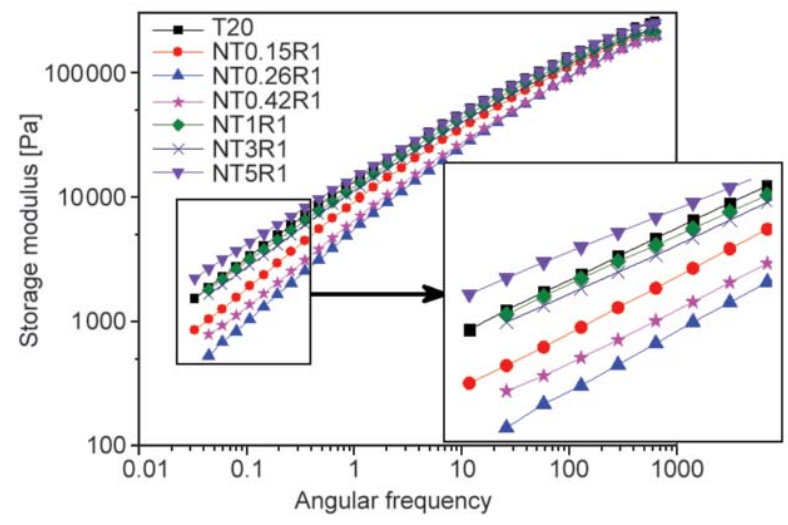

Figure 3. Storage modulus of ternary blend (T20) and nanocomposite samples with different amount of msilica with first order of feeding
HDPE samples [see Figure 2] one can find a similar trend for these two sets of nanocomposite samples. These suggests that in the first feeding route both kinetic and thermodynamic parameters act in the favor of localization of silica in HDPE matrix.

Figure 4 compares the storage modulus $\left(G^{\prime}\right)$ of the nanosilica filled ternary blends prepared by different feeding routes. As it is observed, for the sample prepared by the third route addition of nanosilica has a negligible reducing effect on storage modulus compared to that of sample with sequential feeding (NT0.26R1). This suggests that during the time limit

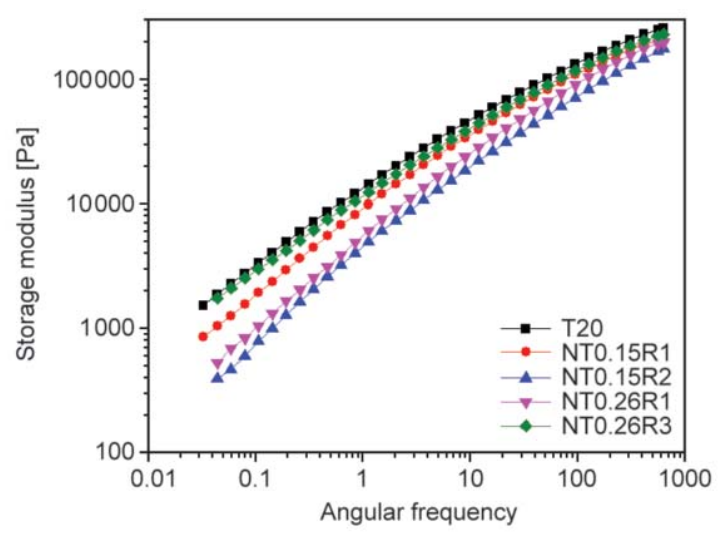

Figure 4. Storage modulus versus frequency of ternary blend (T20) and nanocomposite samples with various feeding routes 
of melt mixing, only small fraction of nanoparticles could migrate from PMMA droplets to favorable HDPE matrix.

The sample containing $0.15 \mathrm{wt} \%$ nanosilica but prepared by the second feeding route exhibits highest reducing effect of nanoparticles on storage modulus. This additional decrease in storage modulus of this sample may be related to decreased contribution of the interface induced elasticity. This is because for this sample the nanoparticles are expected to form aggregates in PS phase resulting in a solid like behavior, which could have a deteriorating effect on coreshell morphology.

\subsection{Morphological study}

Figure $5 \mathrm{a}, 5 \mathrm{~b}$ shows a typical SEM micrograph of cryofractured surface of the HDPE/PS/PMMA $(80 / 7 / 13 \mathrm{wt} \%$ ) ternary blend (Figure $5 \mathrm{a}$ ) after being etched in cyclohexane for 24 hours to resolve the PS phase (Figure 5b). As it can be observed, both SEM micrographs shows a core-shell type morphology. Similar type of morphology has been reported by Reignier and coworkers $[6,7]$ for the same ternary blend system. To insure that the etched phase is the polystyrene phase, a cryofractured surface of HDPE/ PS $(80 / 20 \mathrm{wt} \%)$ was etched and examined by SEM technique. As it can be observed in Figure 5c, the PS droplets are completely removed from the surface of the sample.

Figure 6 shows SEM micrographs of nanosilica filled ternary blend samples containing $0.42,1$ and $3 \mathrm{wt} \%$ nanosilica which were prepared by the sequential feeding. By comparing these SEM micrographs with those observed for unfilled samples in Figure $5 \mathrm{a}, 5 \mathrm{~b}$ one can notice that these samples also show a core-shell type morphology although not as distinct as the unfilled sample (T20). The cryogenically SEM micrographs of sample NT3R1 (with sequential feeding) in which the PS shell was etched out is shown in Figure 6d. As it can be observed a fraction of the nanosilica particles are located on the surface of PMMA core. These particles could be the same particles which were located in the HDPE/PMMA interface before the addition of PS phase and its shell formation. These results are in agreement with thermodynamic prediction for these samples.

The average dimeter of the dispersed particles (coreshell) in these samples are shown in Table 10. As can
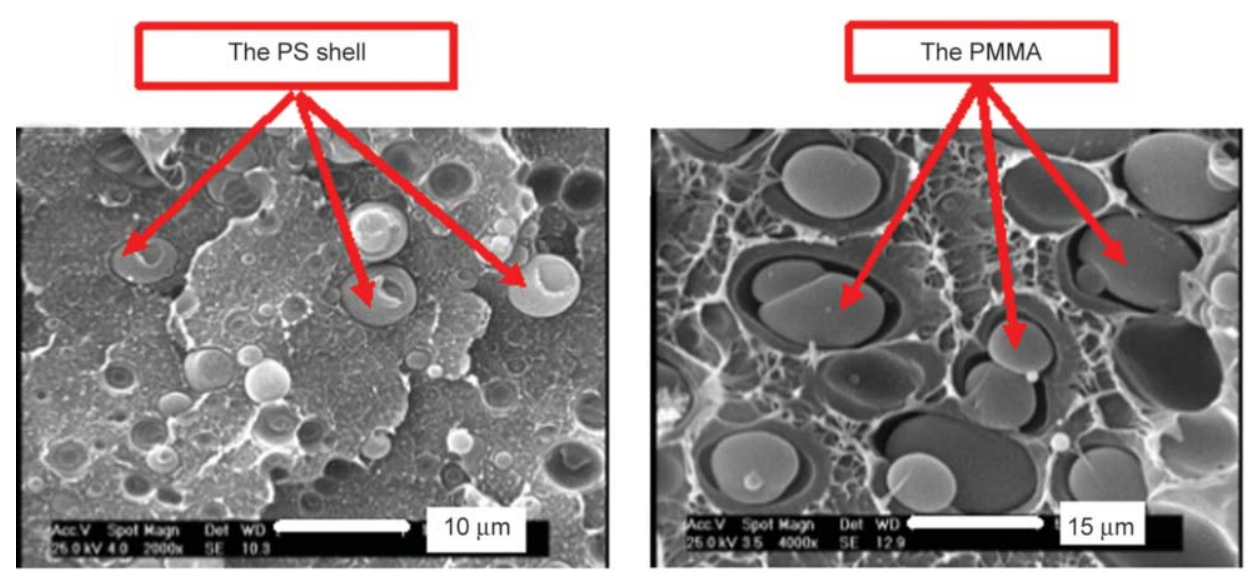

a)

b)

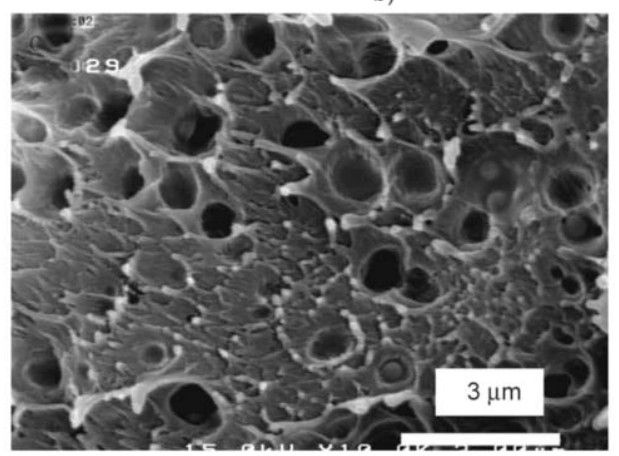

c)

Figure 5. SEM micrographs of a) cryofractured HDPE/PS/PMMA (80/7/13 wt $\%)$ ternary blend and b) the etched HDPE/PS/PMMA (80/7/13 wt\%) ternary blend in cyclohexane c) the etched HDPE/PS (90/10 wt $\%$ ) blend 


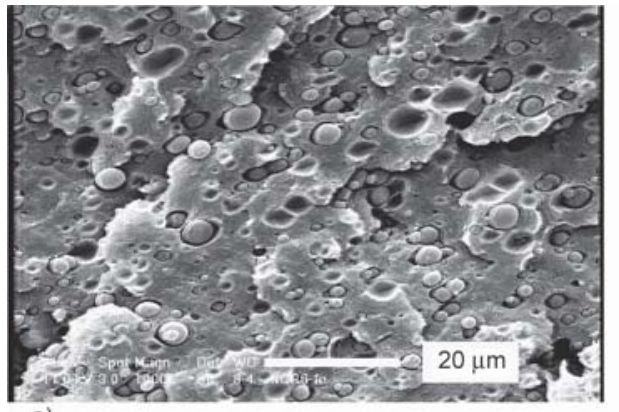

a)

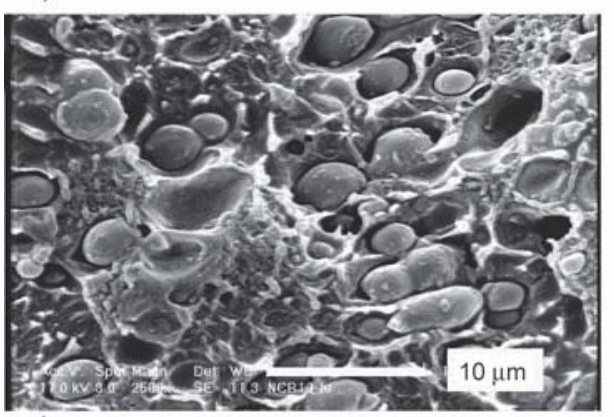

c)

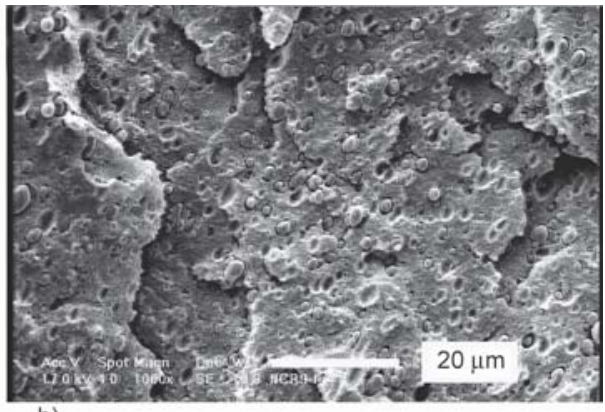

b)

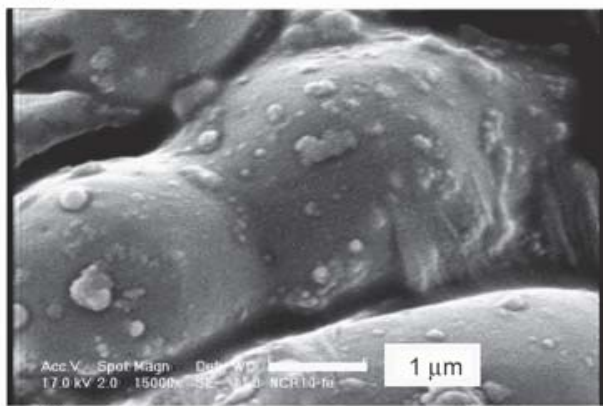

d)

Figure 6. SEM micrographs of croyofractured sample a) NT0.42R1, b) NT1R1 and c) NT3R1 d) zoom of NT3R1 in which the PS shell was etched out by cyclohexane

Table 10. Average dimeter of the dispersed particles in nanocomposite samples based on ternary polymer blends

\begin{tabular}{|c|c|c|c|c|c|}
\hline T20 & NT0.15R1 & NT0.42R1 & NT1R1 & NT3R1 & NT5R1 \\
\hline $4.07 \mu \mathrm{m}$ & $3.46 \mu \mathrm{m}$ & $2.39 \mu \mathrm{m}$ & $1.9 \mu \mathrm{m}$ & $1.6 \mu \mathrm{m}$ & $1.16 \mu \mathrm{m}$ \\
\hline
\end{tabular}

be noticed the particle size is reduced by increasing the nanoparticle loadings up to $1 \mathrm{wt} \%$ of nanosilica above which it remained unchanged. This can mainly be attributed to the compatibilization effect of nanoparticles in reducing the PMMA droplets formation of PS shell, although the hindrance effect of nanoparticles can also play a role. The droplet reducing effect of nanoparticles has been reported by other investigators [12-15, 27]. It has been accepted that reducing the droplet size can have two opposite effect on the storage modulus of polymer blend samples at low frequencies; 1 . the decrease in the storage

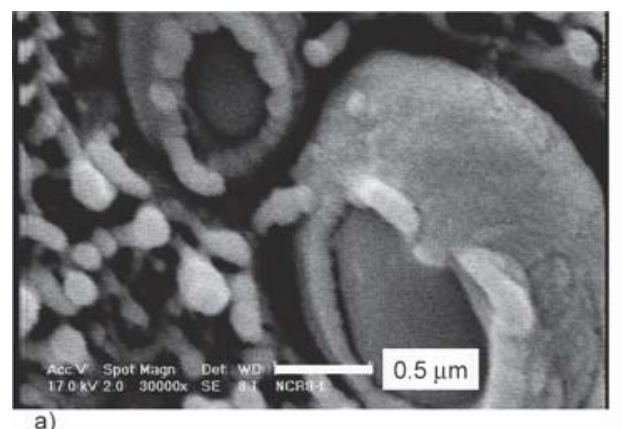

modulus through reducing the droplet deformation induced elasticity, 2. increasing the storage modulus by increasing the interfacial interactions. However since the variation of storage modulus of nanocomposite samples with nanosilica loadings (see Figure 3) follows the same trend as that observed for nanosilica filled HDPE samples (see Figure 2), the results shown in Figure 3 for nanofilled ternary blend samples can be mainly attributed to the effect of preferentially localized nanosilica on reducing the $G^{\prime}$ of the HDPE matrix.

The sample prepared by the third method (PMMA based masterbatch) also showed a core-shell type morphology as can be observed in Figure 7a. This is also in agreement with thermodynamic predictions for the samples in which the nanoparticles were assumed to be mostly localized in PMMA core. In other words for the samples prepared with third route

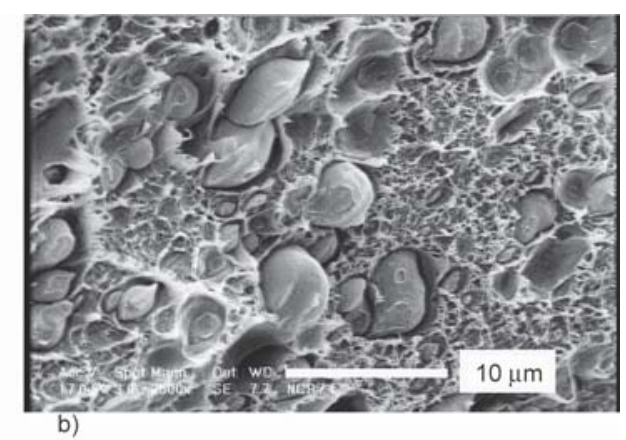

Figure 7. SEM micrograph of croyofractured sample a) NT0.78R3 and b) NT0.42R2 
most of nanoparticle remained in the PMMA and the PMMA/PS interface. In the case of the samples prepared by the second route (PS based masterbatch) however a core shell type morphology could not be observed and only some particles encapsulated by uncompleted shell could be detected (see Figure 7b). This was in the contrast to thermodynamic predictions. We believed that uneven distribution of nanoparticles in PS phase and/or nanoparticle induced elasticity of PS did not allow the PS shell to be completed to spread on PMMA droplets to form a complete shell.

\section{Conclusions}

The aim of the present work was to study the effect of addition of hydrophobic nanosilica on morphology development of HDPE/PS/PMMA ternary blend. The melt viscoelastic results together with SEM micrographs showed that the addition of nanoparticles could have different effect on morphology development of the ternary blend samples depending on the sequence of feeding. When sequential feeding was used, a core shell type morphology, originally showed by unfilled ternary blends could be observed. A similar results were obtained for the samples in which PMMA was first compounded with nanofiller and used as a master batch. However the core shell morphology could hardly be formed in the nanocomposite where nanofilled PS master batch was used. The core shell morphology formed in the nanofilled samples was suggested to be an indication of predominating the same thermodynamic parameters that controlled the morphology of the unfilled blend samples. The uncompleted shell formed in the samples prepared by using PS master batch was attributed to the flow constraint caused by the solid like elastic behavior of nanosilica filled PS shell.

\section{References}

[1] Reignier J., Favis B. D.: Core-shell structure and segregation effects in composite droplet polymer blends. AIChE Journal, 49, 1014-1023 (2003). https://doi.org/10.1002/aic.690490418

[2] Reignier J., Favis B. D.: Control of the subinclusion microstructure in HDPE/PS/PMMA ternary blends. Macromolecules, 33, 6998-7008 (2000). https://doi.org/10.1021/ma991954g
[3] Mohammadigoushki H., Nazokdast H., Mostofi N.: Morphology development and melt linear viscoelastic properties of (PA6/PP/PS) ternary blend systems. Journal of Elastomers and Plastics, 41, 339-351 (2009). https://doi.org/10.1177/0095244309104461

[4] Luzinov I., Pagnoulle C., Jérôme R.: Ternary polymer blend with core-shell dispersed phases: Effect of the core-forming polymer on phase morphology and mechanical properties. Polymer, 41, 7099-7109 (2000). https://doi.org/10.1016/s0032-3861(00)00057-4

[5] Luzinov I., Xi K., Pagnoulle C., Huynh-Ba C., Jérôme R.: Composition effect on the core-shell morphology and mechanical properties of ternary polystyrene/ styrene-butadiene rubber/polyethylene blends. Polymer, 40, 2511-2520 (1999).

https://doi.org/10.1016/s0032-3861(98)00468-6

[6] Reignier J., Favis B. D.: On the presence of a critical shell volume fraction leading to pseudo-pure droplet behavior in composite droplet polymer blends. Polymer, 44, 5061-5066 (2003).

https://doi.org/10.1016/s0032-3861(03)00490-7

[7] Reignier J., Favis B. D., Heuzey M-C.: Factors influencing encapsulation behavior in composite droplettype polymer blends. Polymer, 44, 49-59 (2003). https://doi.org/10.1016/s0032-3861(02)00684-5

[8] Valera T. S., Morita A. T., Demarquette N. R.: Study of morphologies of PMMA/PP/PS ternary blends. Macromolecules, 39, 2663-2675 (2006). https://doi.org/10.1021/ma052571n

[9] Mostofi N., Nazockdast H., Mohammadigoushki H.: Study on morphology and viscoelastic properties of PP/PET/SEBS ternary blend and their fibers. Journal of Applied Polymer Science, 114, 3737-3743 (2009). https://doi.org/10.1002/app.30612

[10] Li L-P., Yin B., Yang M-B.: Morphology prediction and the effect of core-shell structure on the rheological behavior of PP/EPDM/HDPE ternary blends. Polymer Engineering Science, 51, 2425-2433 (2011). https://doi.org/10.1002/pen.22021

[11] Scaffaro R., Botta L., Mistretta M. C., La Mantia F. P.: Processing - morphology - property relationships of polyamide 6/polyethylene blend-clay nanocomposites. Express Polymer Letters, 7, 873-884 (2013). https://doi.org/10.3144/expresspolymlett.2013.84

[12] Elias L., Fenouillot F., Majeste J. C., Cassagnau P.: Morphology and rheology of immiscible polymer blends filled with silica nanoparticles. Polymer, 48, 6029-6040 (2007). https://doi.org/10.1016/j.polymer.2007.07.061

[13] Hong J. S., Namkung H., Ahn K. H., Lee S. J., Kim C.: The role of organically modified layered silicate in the breakup and coalescence of droplets in PBT/PE blends. Polymer, 47, 3967-3975 (2006). https://doi.org/10.1016/j.polymer.2006.03.077 
[14] Fenouillot F., Cassagnau P., Majesté J-C.: Uneven distribution of nanoparticles in immiscible fluids: Morphology development in polymer blends. Polymer, 50, 1333-1350 (2009).

https://doi.org/10.1016/j.polymer.2008.12.029

[15] Elias L., Fenouillot F., Majesté J. C., Alcouffe P., Cassagnau P.: Immiscible polymer blends stabilized with nano-silica particles: Rheology and effective interfacial tension. Polymer, 49, 4378-4385 (2008).

https://doi.org/10.1016/j.polymer.2008.07.018

[16] Elias L., Fenouillot F., Majesté J-C., Martin G., Cassagnau P.: Migration of nanosilica particles in polymer blends. Journal of Polymer Science Part B: Polymer Physics, 46, 1976-1983 (2008).

https://doi.org/10.1002/polb.21534

[17] Rotrekl J., Matějka L., Kaprálková L., Zhigunov A., Hromádková J., Kelnar I.: Epoxy/PCL nanocomposites: Effect of layered silicate on structure and behavior. Express Polymer Letters, 6, 975-986 (2012). https://doi.org/10.3144/expresspolymlett.2012.103

[18] Gubbels F., Jérôme R., Teyssié P., Vanlathem E., Deltour R., Calderone A., Parenté V., Brédas J. L.: Selective localization of carbon black in immiscible polymer blends: A useful tool to design electrical conductive composites. Macromolecules, 27, 1972-1974 (1994). https://doi.org/10.1021/ma00085a049

[19] Taguet A., Cassagnau P., Lopez-Cuesta J-M.: Structuration, selective dispersion and compatibilizing effect of (nano)fillers in polymer blends. Progress in Polymer Science, 39, 1526-1563 (2014).

https://doi.org/10.1016/j.progpolymsci.2014.04.002

[20] Rostami A., Nazockdast H., Karimi M., Javidi Z.: Role of multiwalled carbon nanotubes localization on morphology development of PMMA/PS/PP ternary blends. Advances in Polymer Technology, 35, 21530/1-21530/10 (2016).

https://doi.org/10.1002/adv.21530

[21] Li W., Spoelstra A, B., Goossens J. G. P.: Morphology and rheological properties of silica-filled poly(carbonate)/poly(methyl methacrylate) blends. Polymer Engineering Science, 55, 1951-1959 (2015).

https://doi.org/10.1002/pen.24036

[22] Sathyanarayana S., Wegrzyn M., Olowojoba G., Benedito A., Giménez E., Hübner C.: Multiwalled carbon nanotubes incorporated into a miscible blend of poly (phenylenether)/polystyrene - Processing and characterization. Express Polymer Letters, 7, 621-635 (2013). https://doi.org/10.3144/expresspolymlett.2013.59

[23] Shrivastava N. K., Maiti S., Suin S., Khatua B. B.: Influence of selective dispersion of MWCNT on electrical percolation of in-situ polymerized high-impact polystyrene/MWCNT nanocomposites. Express Polymer Letters, 8, 15-29 (2014).

https://doi.org/10.3144/expresspolymlett.2014.3
[24] Li L., Ruan W-H., Zhang M-Q., Rong M-Z.: Studies on the selective localization of multi-walled carbon nanotubes in blends of poly(vinylidene fluoride) and polycaprolactone. Express Polymer Letters, 9, 77-83 (2015). https://doi.org/10.3144/expresspolymlett.2015.8

[25] Cassagnau P.: Melt rheology of organoclay and fumed silica nanocomposites. Polymer, 49, 2183-2196 (2008). https://doi.org/10.1016/j.polymer.2007.12.035

[26] Foudazi R., Nazockdast H.: Rheology and morphology of nanosilica-containing polypropylene and polypropylene/liquid crystalline polymer blend. Journal of Applied Polymer Science, 128, 3501-3511 (2013). https://doi.org/10.1002/app.38269

[27] Foudazi R., Nazockdast H.: Rheology of polypropylene/liquid crystalline polymer blends: Effect of compatibilizer and silica. Applied Rheology, 20, 1-9 (2009). https://doi.org/10.3933/ApplRheol-20-12218

[28] Hsieh Y-L.: Liquid transport in fabric structures. Textile Research Journal, 65, 299-307 (1995). https://doi.org/10.1177/004051759506500508

[29] Wu S.: Polymer interface and adhesion. Marcel Dekker, New York (1982).

[30] Guggenheim E. A.: The principle of corresponding states. Journal of Chemical Physics, 13, 253-261 (1945). https://doi.org/10.1063/1.1724033

[31] Brostow W., Hagg Lobland H. E.: Brittleness of materials: Implications for composites and a relation to impact strength. Journal of Materials Science, 45, 242$250(2010)$ https://doi.org/10.1007/s10853-009-3926-5

[32] Hobbs S. Y., Dekkers M. J., Watkins V. H.: Effect of interfacial forces on polymer blend morphologies. Polymer, 29, 1598-1602 (1988). https://doi.org/10.1016/0032-3861(88)90269-8

[33] Harkin W. D.: The physical chemistry of surface film. Reinhold, New York (1952).

[34] Guo H. F., Packirisamy S., Gvozdic N. V., Meier D. J.: Prediction and manipulation of the phase morphologies of multiphase polymer blends: 1 . Ternary systems. Polymer, 38, 785-794 (1997). https://doi.org/10.1016/S0032-3861(96)00571-X

[35] Guo H-F., Gvozdic N. V., Meier D. J.: Prediction and manipulation of the phase morphologies of multiphase polymer blends: II. Quaternary systems. Polymer, 38, 4915-4923 (1997) https://doi.org/10.1016/S0032-3861(97)00011-6

[36] Hemmati M., Nazokdast H., Panahi H. S.: Study on morphology of ternary polymer blends. I. Effects of melt viscosity and interfacial interaction. Journal of Applied Polymer Science, 82, 1129-1137 (2001). https://doi.org/10.1002/app.1947

[37] Hemmati M., Nazokdast H., Panahi H. S.: Study on morphology of ternary polymer blends. II. Effect of composition. Journal of Applied Polymer Science, 82, 1138-1146 (2001). https://doi.org/10.1002/app.1948 
[38] Ravati S., Favis B. D.: Morphological states for a ternary polymer blend demonstrating complete wetting. Polymer, 51, 4547-4561 (2010).

https://doi.org/10.1016/j.polymer.2010.07.014

[39] Legros A., Careau P. J., Favis B. D., Michel A.: Morphology modification by interfacial chemical reaction in a polyester/ethylene vinyl acetate/polyethylene blend. Polymer, 38, 5085-5089 (1997).

https://doi.org/10.1016/S0032-3861(97)00033-5

[40] Jain S., Goossens J. G. P., Peters G. W. M., van Duin M., Lemstra P. J.: Strong decrease in viscosity of nanoparticle-filled polymer melts through selective adsorption. Soft Matter, 4, 1848-1854 (2008).

https://doi.org/10.1039/B802905A
[41] Maurer F. H. J., Schoffeleers H. M., Kosfeld R., Uhlenbroich T.: Analysis of polymer-filler interaction in filled polyethylene. in 'Progress in Science and Engineering of Composites. Tokyo, Japan’ 803-809 (1982).

[42] Sternstein S. S., Zhu A-J.: Reinforcement mechanism of nanofilled polymer melts as elucidated by nonlinear viscoelastic behavior. Macromolecules, 35, 7262-7273 (2002).

https://doi.org/10.1021/ma020482u 